\title{
Fear-Potentiated Startle in Rats Is Mediated by Neurons in the Deep Layers of the Superior Colliculus/Deep Mesencephalic Nucleus of the Rostral Midbrain through the Glutamate Non-NMDA Receptors
}

\author{
Zuowei Zhao ${ }^{1}$ and Michael Davis ${ }^{1,2}$ \\ ${ }^{1}$ Department of Psychiatry and Behavioral Sciences, School of Medicine, and ${ }^{2}$ The Center for Behavior Neuroscience, Emory University, Atlanta, Georgia \\ 30329
}

\begin{abstract}
The amygdala sends heavy and broad projections to the rostral midbrain including the periaqueductal gray (PAG), the deep layers of the superior colliculus/deep mesencephalic nucleus (deep SC/DpMe), and the lateral mesencephalic reticular formation (MRF) that in turn project to the nucleus reticularis pontis caudalis $(\mathrm{PnC})$, an obligatory relay in the primary acoustic startle circuit. Chemical lesions or inactivation of these areas blocked fear-potentiated startle, suggesting that these areas serve as a relay between the amygdala and the PnC. In the present study, we tried to determine more precisely which of these sites were critical for fear-potentiated startle and the role of glutamate receptors in this site in mediating fear-potentiated startle. Local infusion of the non-NMDA receptor antagonist 2,3-dihydroxy6-nitro-7-sulfamoylbenzo $(F)$-quinoxaline (NBQX) dose-dependently blocked fear-potentiated startle when infused into the deep SC/ DpMe before testing but had no effect on baseline startle amplitude. NBQX did not block fear-potentiated startle when infused before training. The same dose of NBQX infused into the dorsal/lateral PAG, the lateral MRF, or the superficial layers of the SC did not affect fear-potentiated startle. However, NBQX tended to reduce contextual freezing when infused into the dorsal/lateral PAG. These findings suggest that the deep SC/DpMe is the site that serves as a critical output relay between the amygdala and the PnC in mediating fearpotentiated startle and that glutamatergic transmission is required for this action.
\end{abstract}

Key words: amygdala; PnC; PAG; AMPA; NBQX; context

\section{Introduction}

The fear-potentiated startle effect [increased acoustic startle amplitude when startle is elicited in the presence of a cue previously paired with footshock (Brown et al., 1951; Davis and Astrachan, 1978)] is critically dependent on the amygdala that projects directly to the nucleus reticularis pontis caudalis (PnC), an obligatory brainstem synapse in the acoustic startle pathway (Davis et al., 1982; Hitchcock and Davis, 1986; Rosen et al., 1991; Lee et al., 1996). Electrolytic lesions of the amygdala (Hitchcock and Davis, 1986) or lesions along this amygdalo-PnC pathway (Hitchcock and Davis, 1991) completely blocked fear-potentiated startle, and this direct pathway was proposed to mediate fear-potentiated startle (Hitchcock and Davis, 1991). However, the amygdala also sends heavy, broad projections to the rostral midbrain (Rosen et

\footnotetext{
Received March 18, 2004; revised 0ct. 5, 2004; accepted 0ct. 5, 2004.

This work was supported by National Institute of Mental Health Grants MH47840, MH57250, and MH59906, the Merck Research Foundation (Z.Z.), and the Science and Technology Center (The Center for Behavioral Neuroscience of the National Science Foundation under Agreement IBN-9876754). We gratefully acknowledge Dr. Gayla Y. Paschall for help in the odor experiment.

Correspondence should be addressed to Dr. Zuowei Zhao, Department of Psychiatry and Behavioral Sciences and Center for Behavioral Neuroscience, Emory University, 954 Gatewood Drive, Atlanta, GA 30329. E-mail: zzhao2@emory.edu.

DOI:10.1523/JNEUROSCI.2758-04.2004

Copyright $\odot 2004$ Society for Neuroscience $\quad 0270-6474 / 04 / 2410326-09 \$ 15.00 / 0$
}

al., 1991; Fendt et al., 1994), which in turn projects to the PnC (Veazey and Severin, 1980; Fendt et al., 1994; Cameron et al., 1995; Meloni and Davis, 1999). Collision tests using electrical brain stimulation suggested that a synapse existed between the amygdala and the midbrain and electrolytic lesions in the midbrain blocked fear-potentiated startle (Yeomans and Pollard, 1993). Thus, the rostral midbrain was proposed to be a relay between the amygdala and the PnC in fear-potentiated startle (Yeomans and Pollard, 1993).

This idea was supported by the fact that chemical, fibersparing lesions of the lateral mesencephalic reticular formation (MRF) in the rostral midbrain blocked fear-potentiated startle (Frankland and Yeomans, 1995), as did chemical lesions of the lateral periaqueductal gray (PAG) (Fendt et al., 1996). In addition, inactivation of the deep layers of the superior colliculus/ deep mesencephalic nucleus (deep SC/DpMe) with muscimol blocked the expression but not the acquisition of fear-potentiated startle (Meloni and Davis, 1999), suggesting an effect on the output circuitry of the amygdala rather than a blockade of sensory input to the amygdala. Although these results confirmed a critical relay in the midbrain in mediating fear-potentiated startle, the precise part of the midbrain remained unclear. Lesions directed to the PAG (Fendt et al., 1996) or MRF (Frankland and Yeomans, 1995) both included some damage to the deep SC/DpMe that sits 
between the PAG and the MRF. More confined lesions of the dorsal and lateral PAG (Walker and Davis, 1997), or lesions of the auditory thalamus that partially involved in the MRF (Campeau and Davis, 1995), did not block fear-potentiated startle using a visual conditioned stimulus (CS), indirectly implicating the deep $\mathrm{SC} / \mathrm{DpMe}$ as the critical site that mediates fear-potentiated startle.

Recently, we found that local infusion of the AMPA/kainate glutamatergic receptor antagonist 2,3-dihydroxy-6-nitro-7sulfamoylbenzo $(F)$-quinoxaline $(\mathrm{NBQX})$ has a limited area of diffusion based on infusion sites in the amygdala that do or do not block fear-potentiated startle (D. L. Walker, G. Y. Paschall, and M. Davis, unpublished observations). Here, we used NBQX infusion into each of these highly glutamate-positive areas (Jones, 1994) to evaluate the critical site of the rostral midbrain in mediating fear-potentiated startle. We also tested whether NBQX infusion into the deep SC/DpMe would block the expression, but not the acquisition, of fear-potentiated startle.

\section{Materials and Methods Subjects}

Male Sprague Dawley rats (Charles River, Raleigh, NC), weighing 400$450 \mathrm{gm}$ at the time of surgery, were used in this study. Animals were housed in groups of four in plastic cages until surgery, after which they were housed singly in a hanging wire cage $(18 \times 25 \times 20 \mathrm{~cm})$. Rats were maintained on a $12 \mathrm{hr}$ light/dark cycle (lights on from 7:00 A.M. to 7:00 P.M.) with food and water available ad libitum. This work was performed under conditions consistent with the U.S. Department of Agriculture, Emory University, and National Institutes of Health rules for the care and use of laboratory animals.

\section{Cannula implantation}

Before the behavioral experiments, rats were anesthetized with Nembutal (sodium pentobarbital; 50 mg/kg, i.p.; Emory University School of Medicine Pharmacy, Atlanta, GA) and placed in a stereotaxic instrument (model 900; Kopf, Tujunga, CA) with blunt ear bars. The skull was exposed, and stainless steel guide cannulas (22 gauge; Plastics One, Roanoke, VA), which were occluded with an internal dummy stylette extending $1 \mathrm{~mm}$ beyond the guide cannula tip, were bilaterally lowered into the brain aiming at the deep SC/DpMe [anteroposterior (AP), -6.6 $\mathrm{mm}$; mediolateral (ML), $+/-1.5 \mathrm{~mm}$; dorsoventral (DV), $-5.0 \mathrm{~mm}$ with respect to bregma and dura], the dorsal/lateral PAG (AP, $-6.6 \mathrm{~mm}$; ML, $+/-0.5 \mathrm{~mm}$; DV , $-5.0 \mathrm{~mm}$ ), the lateral MRF (AP, $-6.6 \mathrm{~mm}$; ML, +/-2.5 $\mathrm{mm} ; \mathrm{DV},-5.0 \mathrm{~mm})$, or the superficial SC (AP, $-6.6 \mathrm{~mm}$; ML. $+/-1.5 \mathrm{~mm}$; $\mathrm{DV},-3.3 \mathrm{~mm}$ ). The cannulas were anchored with dental cement to four jeweler screws that were previously attached to the skull. Animals were given $7 \mathrm{~d}$ for recovery before the behavioral study began.

\section{Startle apparatus}

Rats were trained and tested in four identical stabilimeters located in separate chambers $(90 \times 70 \times 70 \mathrm{~cm})$ that were dark, ventilated, and sound attenuated. Each stabilimeter consisted of an $8 \times 15 \times 15 \mathrm{~cm}$ Plexiglas and wire mesh cage and was suspended within a steel frame by four compression springs. The floor of each cage consisted of four stainless steel bars (6 $\mathrm{mm}$ in diameter and $18 \mathrm{~mm}$ apart), through which footshocks were delivered. An accelerometer (PCM Piezotronics, Depew, NY) was affixed to the bottom of the cage to detect any movement of the cage. The displacement of the accelerometer caused by cage movement generated voltage that was integrated and proportional to the velocity of cage movement. The analog output of the accelerometer was amplified (model 483B21; PCB, Piezotronics) and digitized on a scale of 0-2500 U by an InstruNET device (model 100B; GW Instruments, Somerville, MA) interfaced to a Macintosh G3 computer. The amplitude of startle response was defined as the maximal peak-to-peak voltage that occurred during the first $200 \mathrm{msec}$ after onset of the startle-eliciting stimulus. Using the cage arrangement described above, the very abrupt, short-latency, startle reflex (e.g., 8 msec recorded with electromyography in the hindleg) leads to an initial downward cage movement with a latency of 13-15 msec, followed by a short series of upward and downward cage movements that are rapidly damped, ending in $\sim 180 \mathrm{msec}$ (Cassella and Davis, 1986). Hence, the $200 \mathrm{msec}$ sampling window allows the highest peak-to-peak movement of the cage to be accurately sampled. The total duration of cage movement does not reflect additional movement of the animal beyond 15-20 msec but simply the integrated output of the accelerometer under these conditions in which it is compressed between the cage and compression springs above and the rubber stopper below (Cassella and Davis, 1986). The startle reflex does not involve any additional movement and is fully described by two afferent volleys to spinal motor neurons with latencies of 8 and $13 \mathrm{msec}$ (Boulis et al., 1990). The output of the accelerometer over a $200 \mathrm{msec}$ window also was used to measure activity in the absence of a startle stimulus as a measure of freezing to context after fear conditioning (Gewirtz et al., 1997). A surveillance camera (Burle model TC 651B with a TC 9907a lens; Operational Security Systems, Atlanta, GA) was positioned behind each stabilimeter and connected to a television monitor located outside the chamber. Background illumination was provided by a red incandescent bulb $(7.5 \mathrm{~W})$ located $11 \mathrm{~cm}$ above the stabilimeter.

A high-frequency speaker (Radio Shack Super-tweeters; range, 5-40 $\mathrm{kHz}$ ) was positioned $5 \mathrm{~cm}$ from the front of each stabilimeter. Constant background white noise $(60 \mathrm{~dB})$ was generated by a General Radio noise generator (ACO Pacific, Belmont, CA) and delivered through the speaker. The acoustic startle stimulus was a $50 \mathrm{msec}$ white noise burst (5 msec rise-decay) generated by the Macintosh G3 computer $(0-22 \mathrm{kHz})$ and delivered through the same speaker to evoke startle response. The background noise and the white noise burst were amplified by a Radio Shack amplifier (100 W; model MPA-200). The intensity of the sounds was frequently calibrated with a sound level meter (model 2235; Bruel \& Kjaer, Marlborough, MA) at the distance that approximated the distance of the rat's ear to the speaker.

The visual CS was a $3.7 \mathrm{sec}$ light (70 lux) produced by an $8 \mathrm{~W}$ fluorescent bulb (100 $\mu \mathrm{sec}$ rise time, measured by a photocell connected to a storage oscilloscope) that was located $15 \mathrm{~cm}$ behind each stabilimeter. The olfactory CS was a $4 \mathrm{sec}$ odor of 5\% amyl acetate (Sigma, St. Louis, $\mathrm{MO})$ diluted in propylene glycol. This odor was delivered through an olfactometer (model E15-03; Coulbourne Instruments, Allentown, PA) mounted outside the chamber as described previously (Paschall and Davis, 2002). The olfactometer allowed the odor to be blended with an otherwise steady flow of air at an overall rate of $2 \mathrm{l} / \mathrm{min}$. The unconditioned stimulus (US) was a $0.5 \mathrm{sec}, 0.4 \mathrm{~mA}$ shock produced by four shock generators (SGS-004; LeHigh Valley, Beltsville, MD) located outside the chamber and delivered to the floor bars of each stabilimeter. Shock intensity was measured with a $1 \mathrm{k} \Omega$ resistor across a differential channel of an oscilloscope in series with a $100 \mathrm{k} \Omega$ resistor connected between adjacent floor bars within each stabilimeter. Current was defined as the root mean square voltage across the $1 \mathrm{k} \Omega$ resistor in which milliamperes equaled $0.707 \times 0.5 \times$ peak-to-peak voltage. The presentation and sequencing of all stimuli were under the control of the Macintosh G3 computer using specially designed software (The Experimenter; Glassbeads, Newton, CT).

\section{Behavioral procedures}

Experiment 1: test for the effects of NBQX on the acquisition of fear-potentiated startle

Matching. After recovery from surgery, rats were given two sessions of matching on 2 consecutive days before training. On each of the matching sessions, animals were placed in the stabilimeter devices for $5 \mathrm{~min}$ without exposure to acoustic startle stimuli (acclimation period). During the $5 \mathrm{~min}$ acclimation period, activity was sampled for $200 \mathrm{msec}$ every $10 \mathrm{sec}$. After the acclimation period, 15 startle-eliciting stimuli (leaders) were given in a semirandom order, five at each of three different intensities $(95,100$, and $105 \mathrm{~dB})$ at a $30 \mathrm{sec}$ interstimulus interval (ISI). The leaders were used to familiarize the rats to the acoustic stimuli and were not used for statistical analysis. Following the leaders, another 45 startle stimuli were presented, 15 at each of the three different intensities with $30 \mathrm{sec}$ ISIs. Rats were then divided into groups that had equivalent mean startle amplitudes across these 45 stimuli. These matching sessions are designed 
to produce some habituation and stabilization of the startle response, and we have proved them useful to include before experimental manipulations.

Drug infusion. Immediately before each of the two training sessions, rats were infused with either the AMPA/kainate receptor antagonist NBQX (disodium; Tocris, Avonmouth, Bristol, UK) or artificial CSF (ACSF). NBQX was freshly prepared at the following doses: $7.9 \mathrm{nmol}(3$ $\mu \mathrm{g})$ and $0.79 \mathrm{nmol}(0.3 \mu \mathrm{g})$ in $0.5 \mu \mathrm{l}$ of ACSF. During the drug infusion, rats were placed in individual plastic cages $(28 \times 17 \times 12 \mathrm{~cm})$, the dummy stylettes were removed, and the infusion cannulas ( 28 gauge; 1 $\mathrm{mm}$ projection from the tip of the guide cannula; Plastics One) were inserted. The infusion cannulas were attached to microsyringes $(10 \mu \mathrm{l}$; Hamilton, Reno, NV) by polythylene tubing, and the drug solutions were delivered into the deep SC/DpMe or the dorsal/lateral PAG by a Harvard Apparatus (South Natick, MA) pump (model 22) at $0.25 \mu \mathrm{l} / \mathrm{min}$ for 2 min for a total $0.5 \mu \mathrm{l}$ drug solution in each infusion site. The infusion cannulas remained in place for another $2 \mathrm{~min}$ after infusion and then removed, and the dummy stylettes were replaced.

Training. Rats were presented with either light or an odor as a CS that was paired with a mild footshock during training for fear conditioning. For training with light-shock pairing, two sessions of training were given $24 \mathrm{hr}$ apart. On each of the training sessions, rats were placed in the stabilimeter devices and activity was sampled for $5 \mathrm{~min}$, identical to the matching session. Immediately thereafter, rats were given 10 light-shock pairings that consisted of a $3.7 \mathrm{sec}$ light and a $0.5 \mathrm{sec}, 0.4 \mathrm{~mA}$ footshock that coterminated simultaneously. The mean intertrial interval was $3 \mathrm{~min}$ (range, 2-4 min). For odor-shock training, only one session was used that consisted of five odor-shock pairings, using a 4 sec odor coterminating with a $0.5 \mathrm{sec}, 0.4 \mathrm{~mA}$ footshock, a procedure sufficient to produce reliable fear-potentiated startle to olfactory CSs (Paschall and Davis, 2002). The rest of procedures were identical to those in light-shock training.

Fear-potentiated startle testing. Two days after training, rats were returned to the stabilimeters and presented with the acclimation and leaders identical to the matching sessions, followed by 30 startle stimuli in the presence of light [light-noise (LN) trials] and 30 stimuli in the absence of light [noise-alone (NA) trials], 10 of each of the three intensities $(95,100$, and $105 \mathrm{~dB}$ ) with a $30 \mathrm{sec}$ ISI. On the LN trials, the startle stimulus occurred $3.2 \mathrm{sec}$ after the onset of the light, the same time point as the footshock was given in the training sessions. The LN and NA trials were presented in a balanced, pseudorandom order with the constraint that each trial type occurred only once in each consecutive six-trial block (LN or NA $\times 95,100$, and $105 \mathrm{~dB}$ ). For the odor-shock-paired group, 30 leaders were followed by 40 startle stimuli at $95 \mathrm{~dB}$ that consisted of 10 blocks of four startle stimuli presented at a $30 \mathrm{sec}$ ISI. On the first and every fourth stimulus thereafter, startle was elicited $3.5 \mathrm{sec}$ after the onset of the 4 sec odor (odor-noise trial). We found this to be a sensitive way to measure odor-mediated fear-potentiated startle (Paschall and Davis, 2002).

\section{Experiment 2: effects of $N B Q X$ on the expression of fear-potentiated startle}

The matching and training procedures were identical to those in experiment 1 , except that there were no intracerebral drug infusions before the training sessions. To minimize the animal numbers used in this study, rats previously trained with light-shock pairing in experiment 1 were given one session of retraining $3 \mathrm{~d}$ after fear-potentiated startle testing and were used in experiment 2 . We found that the retrained rats previously infused with drug and subsequently trained showed similar fear conditioning and drug response as did naive rats (Meloni and Davis, 1999; the present study). For retraining, rats received five light-shock pairings using the same procedures described in experiment 1 .

Short test. One day after training/retraining, rats were given a $5 \mathrm{~min}$ acclimation period and 15 leaders, followed by five LN and five NA trials at $95 \mathrm{~dB}$ in a pseudorandom order. The startle amplitudes on the LN and NA trials were used to match rats into groups so that each of the groups had equivalent mean startle amplitudes on the LN and NA trials. Rats previously trained and tested for the acquisition of fear-potentiated star- tle were distributed evenly across groups as a function of their previous drug infusion treatments (i.e., NBQX or ACSF).

Test for the expression of fear-potentiated startle. One day after the short test, rats were infused with drugs and immediately tested for fearpotentiated startle, using drug infusion and test procedures identical to those described in experiment 1 . Briefly, rats were infused with NBQX $(0.16,0.79$, or $7.9 \mathrm{nmol})$ or ACSF into the deep SC/DpMe. In addition, other groups were infused with NBQX $(0.79 \mathrm{nmol}$ or $7.9 \mathrm{nmol})$ or ACSF into the dorsal/lateral PAG, the lateral MRF, or the superficial SC. Immediately after infusion, rats were returned to the stabilimeter devices and tested for fear-potentiated startle with the program identical to experiment 1 . To address the issue as to whether previously trained and tested rats might have biased the results, eight additional rats were trained using the training protocol of experiment 1 first, but without any pretraining drug infusion, and $48 \mathrm{hr}$ later were infused with NBQX or ACSF into the deep SC/DpMe and immediately tested for the expression of fear-potentiated startle.

\section{Histology}

At the end of the experiments, rats were given an overdose of chloral hydrate and perfused intracardially with $0.9 \%$ saline, followed by $8 \%$ buffered formalin. The brains were removed from the skull and immersed in a $30 \%$ sucrose-formalin solution for at least $3 \mathrm{~d}$. The brains were later cut by $40 \mu \mathrm{m}$ coronal sections at the level of the midbrain. Every third section was mounted on gelatin-coated slides, air dried, and stained with cresyl violet. The location of the cannulas was assessed under a light microscope and transcribed onto a brain atlas (Paxinos and Watson, 1997).

\section{Statistical analyses}

Mean startle amplitude, collapsed across startle stimulus intensity and session, was computed on the LN and NA trials and analyzed with paired $t$ tests within each of the groups. To analyze between-group differences in fear-potentiated startle, the percentage of potentiation [((LN - NA)/ NA) $\times 100$ ] was analyzed with univariate ANOVA using the SPSS (Chicago, IL) statistical package. If ANOVA yielded a significance of 0.05 , post hoc analysis with two-tailed Dunnett's comparison was used to compare differences between the ACSF group and each of the NBQX-treated groups. Activity suppression during the first $5 \mathrm{~min}$ when rats were returned to the stabilimeters after fear conditioning was analyzed as contextual freezing index, which was defined as pretraining activity-posttraining activity. Fear-induced activity suppression was used as another measure of fear and has proven to correlate highly with freezing measured by observation (Gewirtz et al. 1997; Anagnostaras et al. 1999). The freezing behavior was analyzed only for the intra-PAG infusion of NBQX because our pilot study showed no effect of intra-deep SC/DpMe NBQX on the activity suppression induced by fear conditioning.

\section{Results}

\section{Cannula placement}

The locations of cannula tips into the deep SC/DpMe, the dorsal/ lateral PAG, the lateral MRF, and the superficial SC are illustrated in Figure 1. The locations of the cannula tips in the deep SC/ DpMe are illustrated by the shaded area in the left panel with some squares and circles that are an example of the infusion with ACSF and $0.79 \mathrm{nmol}$ of NBQX. The cannula placements in the deep SC/DpMe were at the junction between the deep layers of the superior colliculus (DpWh and DpG) and the deep mesencephalic nucleus (DpMe), with the center at the level across the aqueduct Sylvius. Starting from this point, as illustrated in the right panel of Figure 1, $1 \mathrm{~mm}$ medial to this area was the location of the dorsal/lateral PAG that included dorsolateral and lateral PAG (DLPAG and LPAG). One millimeter lateral to this area was the infusion site of the lateral MRF that included the lateral portion of the intermediate gray layer of the superior colliculus (InG) and the lateral portion of the DpMe, and $1.7 \mathrm{~mm}$ dorsal to this area was superficial SC that was predominantly composed of su- 


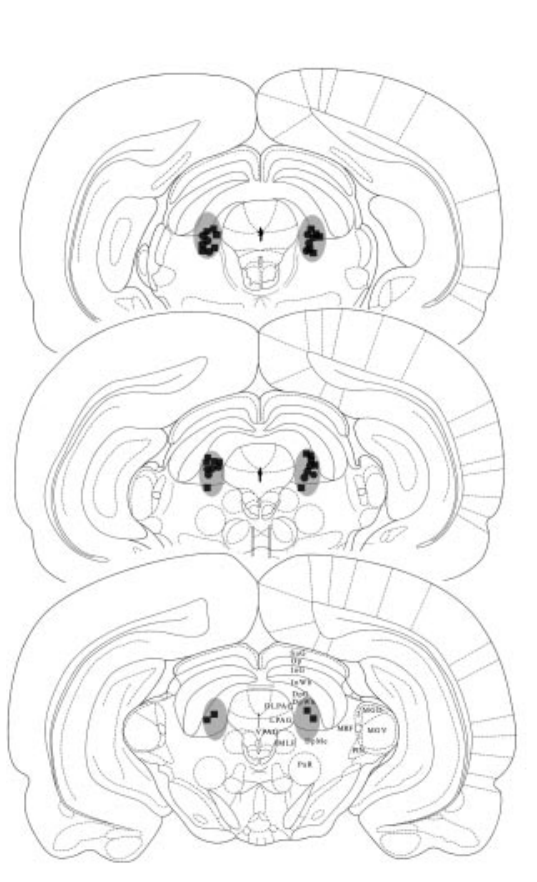

Deep SC/DpMe

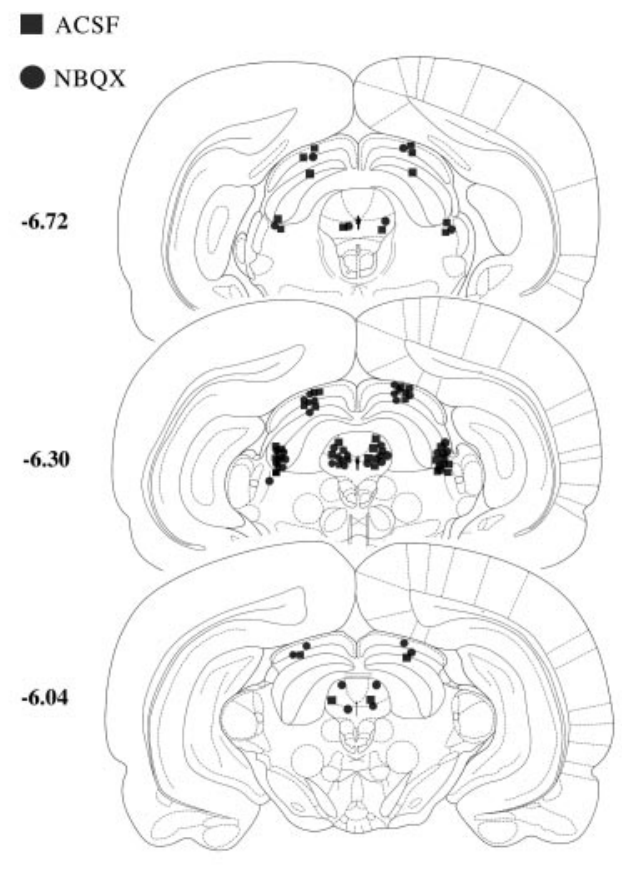

PAG, MRF or superficial SC

Figure 1. The locations of the tips of the infusion cannulas in the deep SC/DpMe, the dorsal/lateral PAG, the lateral MRF, or the superficial SC. The closed squares represent the cannula placements with ACSF infusion, and the closed circles represent the cannula placements with NBQX infusion. In the deep SC/DpMe, because of a large number of the cannulas implanted, the cannula placements are generally illustrated with the shaded area (left) with some squares and circles that are an example of the infusion of ACSF and $0.79 \mathrm{nmol}$ of NBQX. The right panel illustrates the cannula placements in the PAG, the MRF, or the superficial SC, in which NBQX infusion was ineffective in blocking potentiated startle. MGM, Medial geniculate nucleus, medial part; SG, suprageniculate thalamic nucleus; DLPAG, the dorsolateral periaqueductal gray; DpG, deep gray layer of the superior colliculus; DpWh, deep white layer of the superior colliculus; IMLF, interstitial nucleus of the medial longitudinal fasciculus; InG, intermediate gray layer of the superior colliculus; InWh, intermediate white layer of the superior colliculus; LPAG, lateral periaqueductal gray; MGD, medial geniculate nucleus, dorsal part; MGV, medial geniculate nucleus, ventral part; $0 \mathrm{p}$, optic nerve layer of the superior colliculus; PIN, posterior intralaminar thalamic nucleus; PaR, pararubral nucleus; SuG, superficial gray layer of the superior colliculus; VPAG, ventral periaqueductal gray.

perficial gray and optic nerve layers of the superior colliculus (SuG and Op).

\section{Effect of NBQX infusion into the deep SC/DpMe on the acquisition of fear-potentiated startle}

Figure 2 shows that pretraining infusion of NBQX into the deep SC/DpMe did not block the acquisition of fear-potentiated startle. As illustrated in the top panel, in rats infused with NBQX into the deep SC/DpMe before training with the visual CS, the startle amplitude was significantly higher on the LN trials than on the NA trials in each of the treatment groups $\left(t_{(11)}=5.808, p<0.001\right.$ for ACSF; $t_{(7)}=4.079, p<0.01$ for $0.79 \mathrm{nmol}$ of NBQX; $t_{(11)}=$ $3.945, p<0.01$ for $7.9 \mathrm{nmol}$ of NBQX, respectively; all $p$ values for $t$ tests are two-tailed probabilities). Moreover, as shown by the gray bars depicting the percentage of potentiated startle, there was no significant difference in the magnitude of the percentage of potentiation in the various groups $\left(F_{(2,32)}=0.754 ; p>0.05\right)$. Similarly in rats trained with the olfactory CS (bottom panel), pretraining infusion of NBQX (7.9 nmol) into the deep SC/ DpMe also failed to affect the acquisition of potentiated startle because there was no difference in the magnitude of the percentage of potentiation between the control and NBQX groups $\left(F_{(1,12)}=0.164 ; p>0.05\right)$.

\section{Effect of NBQX infusion into the deep $\mathrm{SC} / \mathrm{DpMe}$ on the expression of fear-potentiated startle}

Figure 3 shows that pretesting infusion of NBQX into the deep SC/DpMe did block the expression of fear-potentiated startle using either the visual or the olfactory CS. The top panel shows that NBQX, infused into the deep SC/DpMe before testing with the visual CS, dose-dependently blocked fear-potentiated startle. A oneway ANOVA yielded a significant difference in the percentage of potentiation of startle among the four treatment groups $\left(F_{(3,41)}=8.552 ; p<0.001\right)$. Subsequent comparisons with two-sided Dunnett's test comparing the ACSF group to each of the drug-treated groups showed significantly less fear-potentiated startle in the 0.79 and 7.9 nmol NBQX groups $(p<$ 0.01 and $p<0.001$, respectively) but not in the $0.16 \mathrm{nmol}$ NBQX group ( $p>0.05$ ). Thus, startle amplitude was increased on the LN versus the NA trials in the ACSF group $\left(t_{(11)}=4.007 ; p<0.01\right)$ and the 0.16 nmol NBQX group $\left(t_{(8)}=2.919 ; p<\right.$ $0.05)$ but not in the groups with higher doses of NBQX $\left(0.79 \mathrm{nmol}, t_{(7)}=1.742\right.$, $p>0.05 ; 7.9$ nmol, $t_{(11)}=1.813, p>$ 0.05). The blockade of fear-potentiated startle by pretesting infusion of NBQX into the deep SC/DpMe was unlikely to result from damage of this area caused by the previous two infusions given before training in experiment 1 , because a separate group of rats that did not have previous infusions before training but was only infused before testing with $0.79 \mathrm{nmol}$ of NBQX into the deep SC/DpMe yielded similar results in blocking fear-potentiated startle (Fig. 3, bottom left). Paired $t$ test revealed a significant increase in startle amplitude on the LN trials than on the NA trials in the ACSF group $\left(t_{(3)}=4.007 ; p<0.05\right)$ but not in the 0.79 nmol NBQX group $\left(t_{(3)}=1.579 ; p>0.05\right)$, and the percentage of potentiation of startle was significantly lower in the NBQX group than in the ACSF group $\left(F_{(1,8)}=7.182 ; p<0.05\right)$. Similarly, in rats trained with the olfactory CS, pretesting infusion of NBQX $(7.9 \mathrm{nmol})$ into the deep SC/DpMe also blocked fear-potentiated startle (Fig. 3 , bottom right $)\left(F_{(1,12)}=11.124 ; p<0.01\right)$.

\section{Effect of intra-PAG infusion of NBQX on fear-potentiated startle}

Because $0.79 \mathrm{nmol}$ of NBQX infused into the deep SC/DpMe blocked fear-potentiated startle, we used the same dose to evaluate the role of other amygdala projection sites of the rostral midbrain region in potentiated startle. Figure 4 shows that pretraining infusion (top panel) of NBQX into the PAG did not block the acquisition of fear-potentiated startle. Thus, in rats with pretraining infusions, startle amplitude was significantly higher on the LN trials than on the NA trials in both the control and the drugtreated groups $\left(t_{(7)}=3.095, p<0.05\right.$ for ACSF and $t_{(7)}=3.765$, $p<0.01$ for NBQX, respectively), and there was no difference in the percentage of potentiation of startle between the two groups 

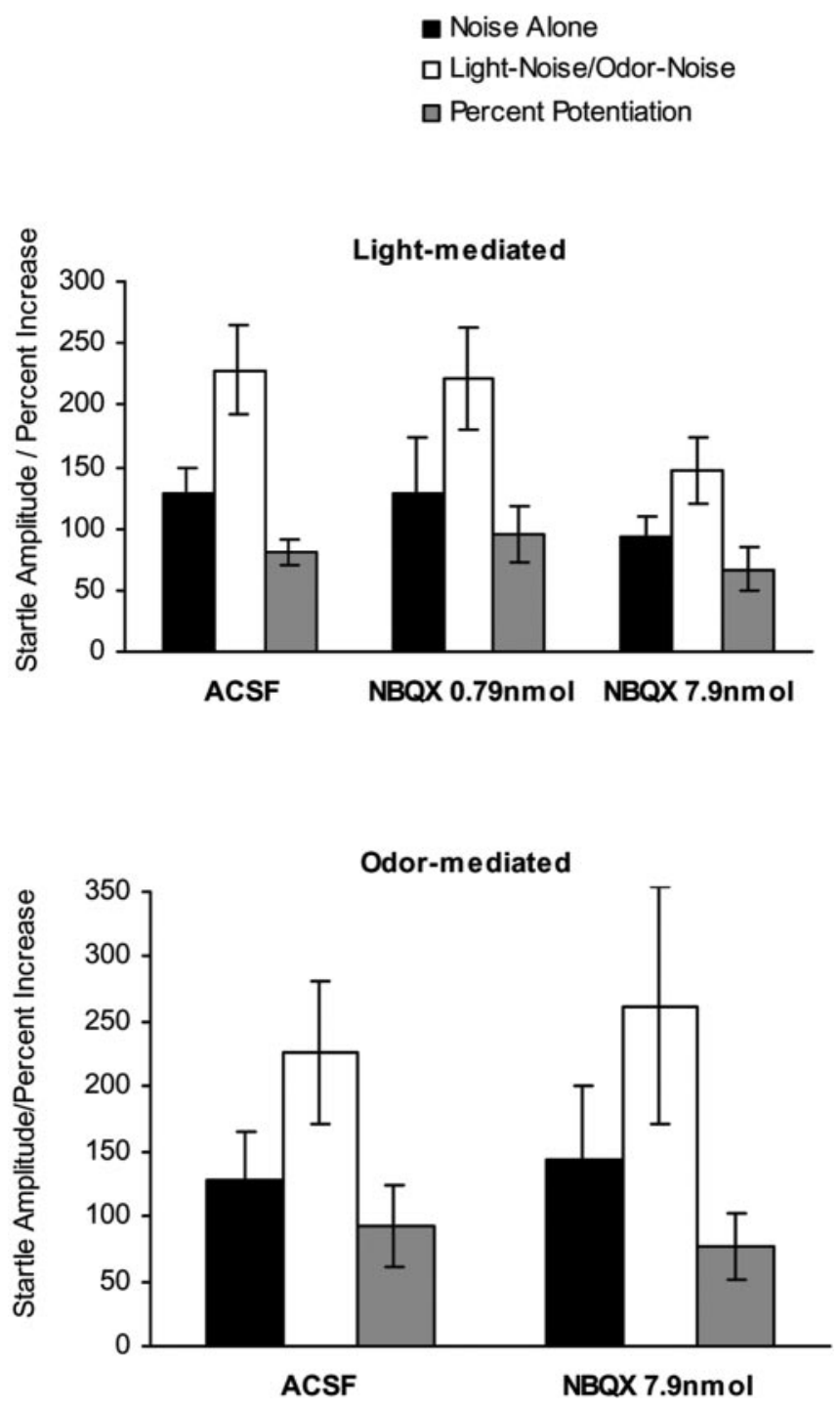

Figure 2. Top, Mean startle amplitude (mean \pm SEM) on the NA ( $\square$ ) and the LN ( $\square$ ) trials and the percentage of potentiation of startle $(\square$; mean \pm SEM) in rats that received infusion of ACSF or NBQX into the deep SC/DpMe before training using light CS (light-mediated). Bottom, Same treatment as in the top panel, except that rats were trained with an odor CS and tested on the NA and the odor-noise trials (odor-mediated). The legend is used for both of these two panels as well as the panels in Figure 3.

$\left(F_{(1,16)}=0.02 ; p>0.05\right)$. Unlike the effect of NBQX in the deep SC/DpMe, however, pretesting infusion (Fig. 4, middle) of NBQX into the PAG did not block the expression of fearpotentiated startle. Thus, startle amplitude was higher on the LN trials in both groups $\left(t_{(7)}=3.846, p<0.01\right.$ for ACSF and $t_{(7)}=$ $2.409, p<0.05$ for NBQX, respectively), and there was no difference in the percentage of potentiation between the groups $\left(F_{(1,16)}=0.450 ; p>0.05\right)$. Pretraining infusion also did not affect context-induced freezing (Fig. 4 , bottom) $\left(F_{(1,16)}=1.253 ; p>\right.$ $0.05)$. In contrast, pretesting infusion of NBQX tended to reduce freezing when compared with infusion of ACSF, although this difference was not statistically significant (Fig. 4, bottom) $\left(F_{(1,16)}=3.096 ; p<0.10\right)$.

Effect of intra-MRF and intra-superficial SC NBQX on the expression of fear-potentiated startle

Figure 5 shows that infusion of NBQX into the lateral MRF or into the superficial SC before testing also failed to affect fear-
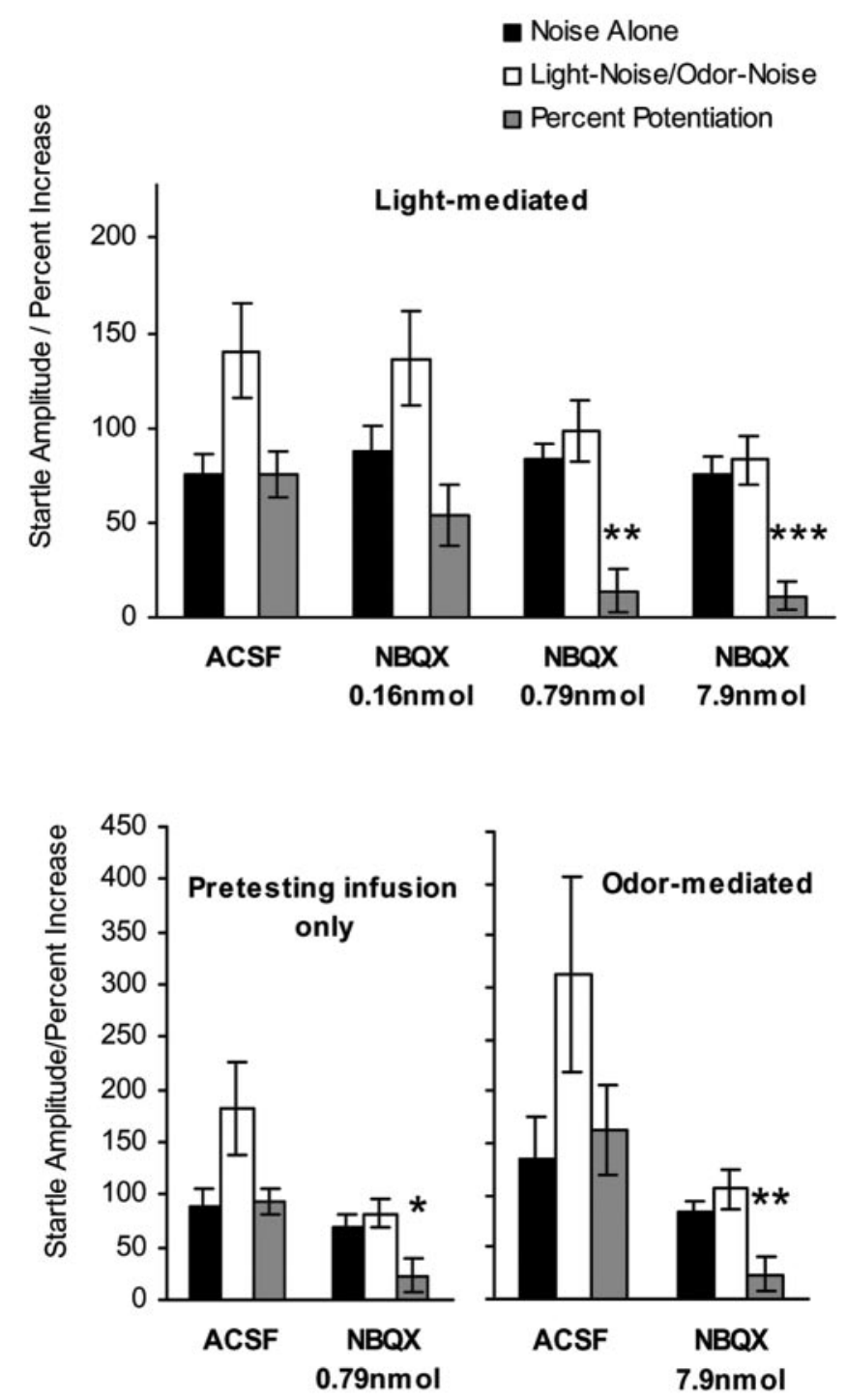

Figure 3. Top, Mean startle amplitude (mean $\pm S E M$ ) on the NA and the LN trials and the percentage of potentiation of startle (mean \pm SEM) in rats that received infusion of ACSF or NBQX into the deep SC/DpMe before testing using light CS. Bottom, Same treatment as in the top panel, except that for the bottom left panel rats were given only pretesting infusion in experiment 2 without previous pretraining infusions in experiment 1. Right, Rats were trained with an odor CS and tested on the NA and the odor-noise trials. ${ }^{*} p<0.05,{ }^{* *} p<0.01$, and ${ }^{* * *} p<0.001$, significance from the ACSF treatment.

potentiated startle. For the intra-MRF infusion (Fig. 5, top), startle amplitude was significantly increased on the LN trials than the NA trials in the ACSF group $\left(t_{(7)}=3.076 ; p<0.05\right)$ and in the NBQX group $\left(0.79 \mathrm{nmol} ; t_{(7)}=2.352 ; p=0.05\right)$, and there was no difference in the percentage of potentiation between the two groups $\left(F_{(1,16)}=0.042 ; p>0.05\right)$. Similar results were seen with infusion of NBQX into the superficial SC using a higher dose (Fig. 5 , bottom $)\left(t_{(7)}=3.660, p<0.01\right.$ for ACSF and $t_{(7)}=2.422, p<$ 0.05 for $7.9 \mathrm{nmol}$ of NBQX, respectively). ANOVA revealed no difference in the percentage of potentiation between the groups $\left(F_{(1,16)}=0.369 ; p>0.05\right)$.

\section{Discussion}

The present study demonstrated that infusion of the AMPA/kainate glutamate receptor antagonist NBQX into the deep SC/ 

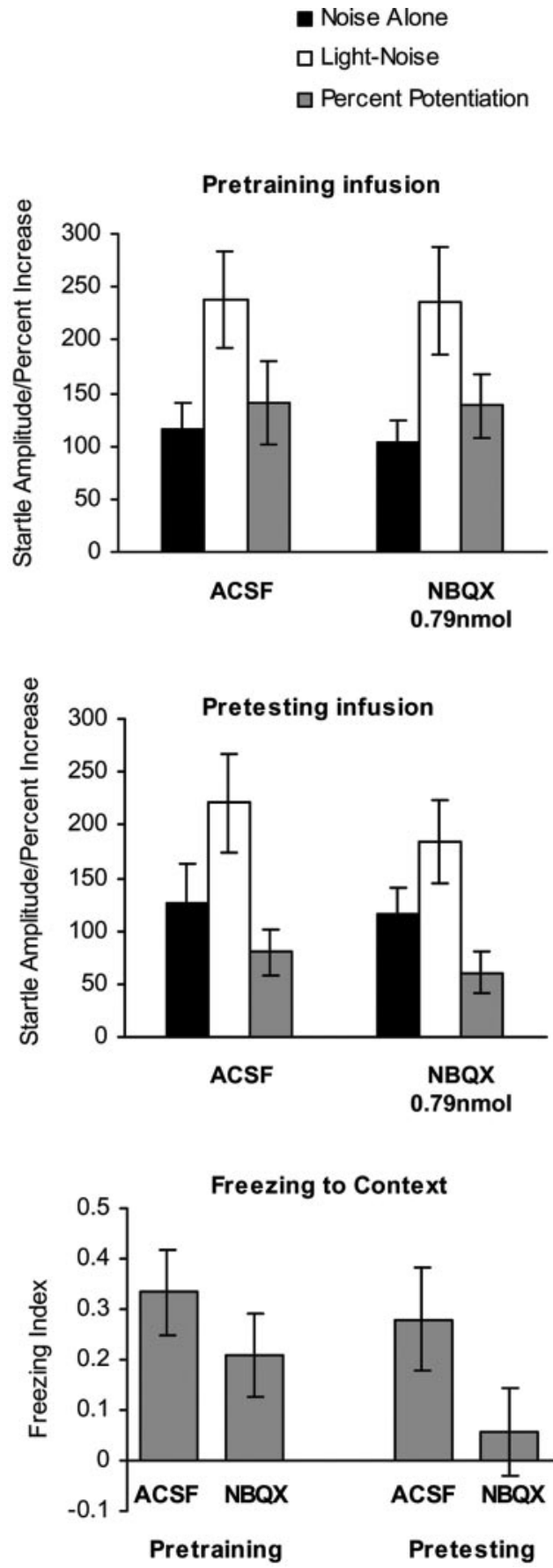

Figure 4. The mean startle amplitude (mean \pm SEM) on the NA and the LN trials and the percentage of potentiation of startle (mean \pm SEM) in rats that received infusion of ACSF or NBQX into the dorsal/lateral PAG before training (top) and before testing (middle) using light CS. The bottom panel is the freezing index to the contextual cue (mean \pm SEM) in the same rats that received intra-PAG infusion of ACSF or NBQX before training or before testing.

DpMe of the rostral midbrain dose-dependently blocked the expression, but not the acquisition, of fear-potentiated startle. Infusion of the same dose of NBQX into the dorsal/lateral PAG, the lateral MRF, or the superficial SC spared fear-potentiated startle. None of the infusions altered the baseline startle response. The results are consistent with previous studies with either lesions of the lateral MRF (Yeomans and Pollard, 1993; Frankland and Yeomans, 1995) or pharmacological inactivation of the deep

\author{
- Noise Alone \\ $\square$ Light-Noise \\ $\square$ Percent Potentiation
}
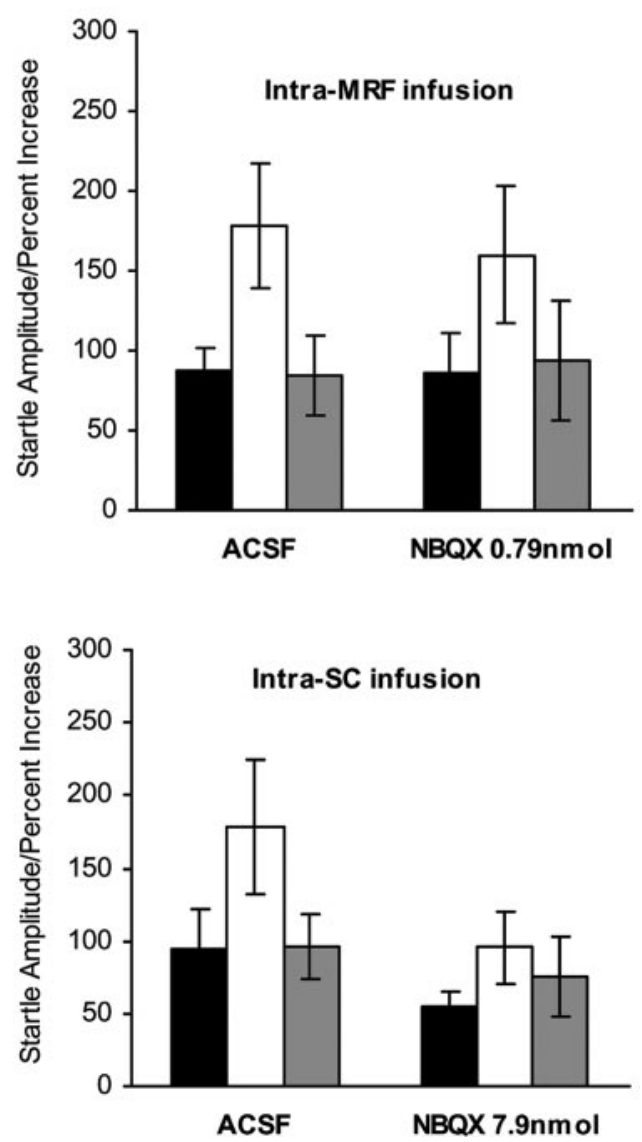

Figure 5. The mean startle amplitude (mean $\pm S E M$ ) on the NA and the LN trials and the percentage of potentiation of startle (mean \pm SEM) in rats that received pretesting infusion of ACSF or NBQX into the lateral MRF (top) or into the superficial SC (bottom).

SC/DpMe (Meloni and Davis, 1999) and support the idea of an indirect amygdalo-tecto-PnC pathway in which the rostral midbrain serves as a relay between the amygdala and the $\mathrm{PnC}$ to mediate fear-potentiated startle (Yeomans and Pollard, 1993). The results of the present study further indicate that the deep $\mathrm{SC} / \mathrm{DpMe}$ is the critical site in the rostral midbrain in mediating fear-potentiated startle and that glutamatergic transmission is required for this action.

In the studies of Yeomans and colleagues, the lesions that blocked fear-potentiated startle centered in the areas $\sim 1.5 \mathrm{~mm}$ ventral [the pararubral nucleus $(\mathrm{PaR})$ ] or $1.0 \mathrm{~mm}$ lateral (lateral $\mathrm{MRF}$ ) to the deep SC/DpMe, but the complete lesion areas overlapped the deep SC/DpMe (Yeomans and Pollard, 1993; Frankland and Yeomans, 1995). This raised the question as to which of these areas was involved in mediating fear-potentiated startle. This question was addressed in the present study by infusion of NBQX into the lateral MRF, and it was found that NBQX in the MRF did not affect fear-potentiated startle. This result is consistent with the finding that NMDA lesions of the auditory thalamic nuclei that resulted in some damage in the lateral MRF did not block fear-potentiated startle using a visual CS (Campeau and Davis 1995). However, another study found that infusion of the NMDA antagonist AP-5 into the same area blocked fear- 
potentiated startle (Schauz and Koch, 2000). Currently, it is not clear how to explain this apparent discrepancy, although it is possible that it was attributable to spread of AP-5 into the deep SC/DpMe. We have not been able to find the same kind of anatomical specificity using AP-5 as we have with NBQX and have found that AP-5 infused into the deep SC/DpMe also blocked the expression of fear-potentiated startle (our unpublished data).

The current results do not support those of Fendt et al. (1996), who reported that fiber-sparing lesions of the lateral PAG blocked fear-potentiated startle. However, these lesions were relatively large, and gliosis was present in the area lateral to the PAG. More confined lesions that covered only the dorsal and lateral PAG did not block fear-potentiated startle (Walker and Davis, 1997), and we did not find that infusion of NBQX into the PAG blocked fear-potentiated startle at a dose that appeared to diminish context-induced freezing, although admittedly only partially, consistent with the known role of the PAG in freezing (Blanchard et al., 1981; Zhang et al., 1990; Kim et al., 1993; Bandler and Shipley, 1994; Fanselow, 1994; Morgan et al., 1998). Because the infusion site of NBQX in this study was in the dorsal/lateral PAG, the incomplete blockade of contextual freezing by NBQX may have been attributable to only partial diffusion into the ventrolateral PAG. It is, of course, possible that the failure to influence fear-potentiated startle by blockade of AMPA/kainate receptors in the PAG may be because glutamate is not required in this area for potentiated startle, although other transmitters here might mediate fear-potentiated startle. For example, the central nucleus of the amygdala contains high concentrations of GABA, so GABA acting in the PAG might mediate fear-potentiated startle. However, based on all these data, we believe that the effective site of the rostral midbrain in mediating fear-potentiated startle is confined to the junction between, and including, the deep SC/DpMe (Fig. 1 ), which is located approximately lateral to the PAG, medial to the lateral part of the intermediate gray layer of the SC (lateral InG), ventral to the superficial layers of the superior colliculus ( $\mathrm{SuG}$ and $\mathrm{Op}$ ), and dorsal to the $\mathrm{PaR}$, although the $\mathrm{PaR}$ remained to be investigated.

The deep SC/DpMe is known to be a sensorimotor interface, where sensory signals (visual, auditory, somatosensory, and nociceptive) converge and integrate, and further provides inputs to the motor output circuitry that guides animals to the stimulus (approach response) and/or initiates certain behavioral responses such as defensive reactions (Meredith and Stein, 1985; Redgrave et al., 1993; Stein and Meredith, 1993). In the deep SC, different sensory modalities can activate a given cell (Meredith and Stein, 1985), and a given sensory stimulus can influence different cells including motor cells that have descending projections to the reticular formation of the brainstem and the spinal cord (Meredith et al., 1992).

Given the multimodal functions of the deep SC/DpMe, a concern may be raised that blockade of fear-potentiated startle by NBQX in the deep SC/DpMe may have resulted from an impairment of the sensory function in this area, particularly the visual, auditory, and nociceptive processing. However, our results make this highly unlikely. When NBQX was given before training, the magnitude of reactivity to footshock was similar between the control and NBQX groups (data not shown), and the infusion did not block the acquisition of fear conditioning that is dependent on nociceptive transmission to shock (Fig. 2). The lack of effect on the acquisition also indicates that visual processing was not impaired. Finally, the fact that infusion of NBQX had no effect on baseline startle amplitude indicates that audition was also intact.
Consequently, it is likely that NBQX acts in the deep SC/ $\mathrm{DpMe}$ on neurons that are involved in fear-induced motor reactions. Among the motor reactivities involved in the deep SC/ DpMe are defensive reactions (Dean et al., 1988; Redgrave et al., 1996; Niemi-Junkola et al., 1997; Brandao et al., 2003), startle response modulation (Meloni and Davis, 2000), convulsions (Garcia-Rill et al., 1985; Hashizume et al., 2000; Ishimoto et al., 2000), and locomotor activity (Sinnamon and Stopford, 1987; Sinnamon et al., 1987; Sinnamon, 1993; Jordan, 1998). The specificity of NBQX infused into this area on fear-potentiated startle compared with baseline startle suggests that amygdala terminals may release glutamate into the deep SC/DpMe when activated by a CS. It is currently not clear, however, whether there is a direct glutamatergic projection from the amygdala to the deep $\mathrm{SC} / \mathrm{DpMe}$, although it has been reported of glutamatergic projections from the central nucleus of the amygdala to other brain regions that have connections with the midbrain (Csaki et al., 2000; Takayama and Miura, 1991). Additional labeling studies using retrograde tracers in the PnC, anterograde tracers in the central nucleus of the amygdala, and immunocytochemistry for glutamate transporters might help clarify this picture.

A recent study in our laboratory found a GABAergic projection from the central nucleus of the amygdala to the deep SC/ DpMe using labeling with GAD67 and retrograde and anterograde tracers (Shi and Davis, 2002). Interestingly, only a few amygdala projection terminals in the deep SC/DpMe were in close proximity to the neurons that project to the $\mathrm{PnC}$, implying that the majority of GABA-containing projections from the amygdala to this area may innervate interneurons rather than output neurons in the deep SC/DpMe. Because local infusion here of either $\mathrm{GABA}_{\mathrm{A}}$ (Meloni and Davis, 1999) or GABA (Zhao $_{\mathrm{B}}$ et al., 2002) agonists blocked the expression of fear-potentiated startle, it is possible that GABAergic transmission in the deep $\mathrm{SC} / \mathrm{DpMe}$ is also involved. If so, we speculate that glutamate would act directly on the output neurons in the deep SC/DpMe, whereas GABA might have a disinhibitory effect via inhibitory interneurons that could be tested with local infusion of GABA antagonists or GABA toxins.

Taken together with other literature, the data now indicate that different parts of the midbrain are involved in mediating different measures of conditioned fear, namely fear-potentiated startle and freezing, both of which are dependent on the amygdala. Thus, the deep SC/DpMe, but not the ventral PAG, is critical for fear-potentiated startle but not freezing, and the PAG, but not the deep SC/DpMe, is critical for freezing. Several studies now indicate that fear-potentiated startle and freezing do not always share similar modulation although both are dependent on the amygdala. For example, lesions of the medial prefrontal cortex retard extinction of conditioned fear measured with freezing (Morgan et al., 1993; Quirk et al., 2000) but not fear-potentiated startle (Gewirtz et al. 1997). Similarly, lesions of the dorsal hippocampus block contextual conditioning measured with freezing but not fear-potentiated startle tested in the same animals (McNish et al., 1997). Thus, it is possible that forebrain structures that modulate these two amygdala-dependent measures of fear may act at different sites of the brainstem rather than at the amygdala. This could explain why freezing and fear-potentiated startle do not always correlate and provide a mechanism to explain differential modulation of different aspects of fear behaviors that are sometimes seen. Future studies looking at differential anatomical inputs to the ventral PAG and deep SC/DpMe, as they relate to 
forebrain modulation of different measures of fear, could be used to further substantiate this idea.

\section{References}

Anagnostaras SG, Josselyn SA, Frankland PW, Silva AJ (1999) Computerassisted behavioral assessment of Pavlovian fear conditioning in mice. Learn Mem 7:58-72.

Bandler R, Shipley MT (1994) Columnar organization in the midbrain periaqueductal gray: modules for emotional expression? Trends Neurosci 17:379-389.

Blanchard DC, Williams G, Lee EMC, Blanchard RJ (1981) Taming of wild Rattus norvegicus by lesions of the mesencephalic central gray. Physiol Psychol 9:157-163.

Boulis NM, Kehne JH, Miserendino MJD, Davis M (1990) Differential blockade of early and later components of acoustic startle following intrathecal infusion of 6-cyano-7-nitroquinoxaline-2,3-dione (CNQX) or DL-2-amino-5-phosphonovaleric acid (AP5). Brain Res 520:240-246.

Brandao ML, Troncoso AC, de Souza Silva MA, Huston JP (2003) The relevance of neuronal substrates of defense in the midbrain tectum to anxiety and stress: empirical and conceptual considerations. Eur J Pharmacol 463:225-233.

Brown JS, Kalish HI, Farber IE (1951) Conditional fear as revealed by magnitude of startle response to an auditory stimulus. J Exp Psychol 41:317-328.

Cameron AA, Khan IA, Westlund KN, Willis WD (1995) The efferent projections of the periaqueductal gray in the rat: a Phaseolus vulgarisleucoagglutinin study. II. Descending projections. J Comp Neurol 351:585-601.

Campeau S, Davis M (1995) Involvement of subcortical and cortical afferents to the lateral nucleus of the amygdala in fear conditioning measured with fear-potentiated startle in rats trained concurrently with auditory and visual conditioned stimuli. J Neurosci 15:2312-2327.

Cassella JV, Harty TP, Davis M (1986) Fear conditioning, pre-pulse inhibition and drug modulation of a short latency startle response measured electromyographically from neck muscles in the rat. Physiol Behav 36:1187-1191.

Csaki A, Kocsis K, Halasz B, Kiss J (2000) Localization of glutamatergic/ aspartatergic neurons projecting to the hypothalamic paraventricular nucleus studied by retrograde transport of $\left[{ }^{3} \mathrm{H}\right] \mathrm{D}$-aspartate autoradiography. Neuroscience 101:637-655.

Davis M, Astrachan DI (1978) Conditioned fear and startle magnitude: effects of different footshock or backshock intensities used in training. J Exp Psychol Anim Behav Process 4:95-103.

Davis M, Gendelman DS, Tischler MD, Gendelman PM (1982) A primary acoustic startle circuit: lesion and stimulation studies. J Neurosci 6:791-805.

Dean P, Mitchell IJ, Redgrave P (1988) Responses resembling defensive behavior produced by microinjection of glutamate into superior colliculus of rats. Neuroscience 24:501-510.

Fanselow MS (1994) Neural organization of the defensive behavior system responsible for fear. Psychon Bull Rev 1:429-438.

Fendt M, Koch M, Schnitzler H-U (1994) Lesions of the central gray block the sensitization of the acoustic startle response in rats. Brain Res 661:163-173.

Fendt M, Koch M, Schnitzler H-U (1996) Lesions of the central gray block conditioned fear as measured with the potentiated startle paradigm. Behav Brain Res 74:127-134.

Frankland PW, Yeomans JS (1995) Fear-potentiated startle and electrically evoked startle mediated by synapses in rostrolateral midbrain. Behav Neurosci 109:669-680.

Garcia-Rill E, Skinner RD, Fitzgerald JA (1985) Chemical activation of the mesencephalic locomotor region. Brain Res Bull 330:43-54.

Gewirtz JC, Falls WA, Davis M (1997) Normal conditioned inhibition and extinction of freezing and fear potentiated startle following electrolytic lesions of medial prefrontal cortex. Behav Neurosci 111:712-726.

Hashizume K, Tanaka T, Fujita T, Tanaka S (2000) Generalized seizures induced by an epileptic focus in the mesencephalic reticular formation: impact on the understanding of the generalizing mechanism. Steriotac Funct Neurosurg 74:153-160.

Hitchcock JM, Davis M (1986) Lesions of the amygdala, but not of the cerebellum or red nucleus, block conditioned fear as measured with potentiated startle paradigm. Behav Neurosci 100:11-22.
Hitchcock JM, Davis M (1991) The efferent pathway of the amygdala in volved in conditioned fear as measured with the fear-potentiated startle paradigm. Behav Neurosci 105:826-842.

Ishimoto T, Omori N, Mutoh F, Chiba S (2000) Convulsive seizures induced by $N$-methyl-D-aspartate microinjection into the mesencephalic reticular formation in rats. Brain Res 881:152-158.

Jones BE (1994) Reticular formation. Cytoarchitecture, transmitters and projections. In: The rat nervous system (Paxinos G, ed), pp 155-177. New South Wales: Academic Press Australia.

Jordan LM (1998) Initiation of locomotion in mammals. Ann NY Acad Sci 860:83-93.

Kim JJ, Rison RA, Fanselow MS (1993) Effects of amygdala, hippocampus, and periaqueductal gray lesions on short- and long-term contextual fear. Behav Neurosci 107:1093-1098.

Lee Y, Lopez DE, Meloni EG, Davis M (1996) A primary acoustic startle circuit: obligatory role of cochlear root neurons and the nucleus reticularis pontis caudalis. J Neurosci 16:3775-3789.

McNish KA, Gewirtz JC, Davis M (1997) Evidence of contextual fear conditioning following lesions of the hippocampus: a disruption of freezing but not fear-potentiated startle. J Neurosci 17:9353-9360.

Meloni EG, Davis M (1999) Muscimol in the deep layers of the superior colliculus/mesencephalic reticular formation blocks expression but not acquisition of fear-potentiated startle in rats. Behav Neurosci 113:1152-1160

Meloni EG, Davis M (2000) GABA in the deep layers of the superior colliculus/mesencephalic reticular formation mediates the enhancement of startle by the dopamine D1 receptor agonist SKF 82958 in rats. J Neurosci 20:5374-5378.

Meredith MA, Stein BE (1985) Descending efferents form the superior colliculus relay integrated multisensory information. Science 227:657-659.

Meredith MA, Wallace MT, Stein BE (1992) Visual, auditory and somatosensory convergence in output neurons of the cat superior colliculus: multisensory properties of the tecto-reticulo-spinal projection. Exp Brain Res 88:181-186.

Morgan MA, Romanski LM, LeDoux JE (1993) Extinction of emotional learning: contribution of medial prefrontal cortex. Neurosci Lett 163:109-113.

Morgan MM, Whitney PK, Gold MS (1998) Immobility and flight associated with antinociception produced by activation of the ventral and lateral/dorsal regions of the rat periaqueductal gray. Brain Res Bull 804:159-166.

Niemi-Junkola U, Shehab S, Redgrave P (1997) Anticonvulsant and behavioral effects of bicuculline injected into the mesencephalic locomotor region of rats. Brain Res 778:401-404.

Paschall GY, Davis M (2002) Olfactory-mediated fear-potentiated startle. Behav Neurosci 116:4-12.

Paxinos G, Watson C (1997) The rat brain in stereotaxic coordinates, Ed 3. New York: Academic.

Quirk GJ, Russo GK, Barron JL, Lebron K (2000) The role of ventromedial prefrontal cortex in the recovery of extinguished fear. J Neurosci 20:6225-6231.

Redgrave P, Westby GWM, Dean P (1993) Functional architecture of rodent superior colliculus: relevance of multiple output channels. Prog Brain Res 95:69-77.

Redgrave P, Telford S, Wang S, McHaffie JG, Stein BE (1996) Functional anatomy of nociceptive neurons in rat superior colliculus. Prog Brain Res 107:403-415.

Rosen JB, Hitchcock JM, Sananes CB, Miserendino MJD, Davis M (1991) A direct projection from the central nucleus of the amygdala to the acoustic startle pathway: Anterograde and retrograde tracing studies. Behav Neurosci 105:817-825.

Schauz C, Koch M (2000) Blockade of NMDA receptors in the amygdala prevents latent inhibition of fear-conditioning. Learn Mem 7:393-399.

Shi CJ, Davis M (2002) A GABAergic projection from the central extended amygdala to the dorsolateral deep mesencephalic nucleus in rats. Soc Neurosci Abstr 28:284.14.

Sinnamon HM (1993) Preoptic and hypothalamic neurons and the initiation of locomotion in the anesthetized rat. Prog Neurobiol 41:323-344.

Sinnamon HM, Stopford CK (1987) Locomotion elicited by lateral hypothalamic stimulation in the anesthetized rat does not require the dorsal midbrain. Brain Res Bull 402:78-86. 
Sinnamon HM, Ginzburg RN, Kurose GA (1987) Midbrain stimulation in the anesthetized rat: direct locomotor effects and modulation of locomotion produced by hypothalamic stimulation. Neuroscience 20:695-707.

Stein BE, Meredith MA (1993) The merging of the sense. Cambridge, MA: MIT.

Takayama K, Miura M (1991) Glutamate-immunoreactive neurons of the central amygdaloid nucleus projecting to the subretrofacial nucleus of SHR and WKY rats: a double-labeling study. Neurosci Lett 134:62-66.

Veazey RB, Severin CM (1980) Efferent projections of the deep mesencephalic nucleus (pars medialis) in the rat. J Comp Neurol 190:245-258.

Walker DL, Davis M (1997) Involvement of the dorsal periaqueductal gray in the loss of fear-potentiated startle accompanying high footshock training. Behav Neurosci 111:692-702.

Yeomans JS, Pollard BA (1993) Amygdala efferents mediating electrically evoked startle-like responses and fear potentiation of acoustic startle. Behav Neurosci 107:596-610.

Zhang SP, Bandler R, Carrive P (1990) Flight and immobility evoked by excitatory amino acid microinjection within distinct parts of the subtentorial midbrain periaqueductal gray of the rat. Brain Res Bull 520:73-82.

Zhao ZW, Paschall GY, Davis M (2002) Fear-potentiated startle in rats involves glutamatergic and GABAergic transmission in the deep layers of superior colliculus/mesencephalic reticular formation. Soc Neurosci Abstr 28:284.15. 